\title{
Assessment of Complications and Recurrences After Various Methods of Alloplastic Hernia Defect of the Diaphragm
}

\author{
I Rosenfeld Fsbou In* \\ Tverskaya GMU of the Russian Ministry of Health, Tver City, Russia \\ *Corresponding author: I Rosenfeld Fsbou In, Tverskaya GMU of the Russian Ministry of Health, Tver City, Russia
}

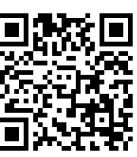

\begin{tabular}{|c|c|}
\hline ARTICLE INFO & ABSTRACT \\
\hline Received: July 07, 2020 & Citation: I Rosenfeld Fsbou In. Assessment of Complications and Recurrences After \\
\hline Published: 蔧 September 22, 2020 & $\begin{array}{l}\text { Various Methods of Alloplastic Hernia Defect of the Diaphragm. Biomed J Sci \& Tech Res } \\
\text { 30(4)-2020. BJSTR. MS.ID.004978. }\end{array}$ \\
\hline
\end{tabular}

\section{Introduction}

The aim of the study is to conduct a review of modern literature on the use of different methods of alloplasty, to identify various postoperative complications and relapses. Analysis of the evidence for alloplasty. Alloplasty of the esophagus of the diaphragm can be performed on 4 basic methods. The most common technique is "onlay" - the strengthening of the posterior cruroraphya, that is, the mesh lining rectangular, triangular or $\mathrm{V}$ - figurative shape to both legs of the diaphragm after they are stitched behind the esophagus. In the review of Furne E. J. V. and co-authors who performed 924 operations, this technique is used in $90 \%$ of cases. In the survey, Frantzides C. T., and co-authors of the "onlay" technique used in $87 \%$ of the plastic herniated diaphragm. The advantage of the technique is the best results in terms of prevention of relapse, as it is the most biomechanical physiological, its shortcomings are: contact of the front edge of the grid with the Oesophagus and the development of postoperative complications, especially if a rigid polypropylene implant is used, as well as the impossibility of plastic defect in front of the esophagus[1-4].

The second common technique is "inlay" - a non-stretch plastic in which a triangular implant is placed behind the esophagus between the legs of the diaphragm without stitching them. Advantage: the possibility of plastics of giant hernia defects, where it is impossible to safely sew atrophic and located at a great distance from each other legs of the diaphragm. The drawbacks of "inlay" plastics are even greater than with the "onlay" technique, the possibility of direct contact of the front edge of the mesh with the Oesophagus and the development of postoperative complications, especially if a rigid polypropylene or polytetrafluoroethylene implant is used, and a high probability of recurrence due to less durable singlelayer plasticity, as well as the prolacle edge of the free implant[5]. Therefore, SAGES' clinical recommendations for the treatment of diaphragm hernias say that this technique cannot be used.The third technique is a modification of the first and consists in "onlay" strengthening of the cruroraphya with a whole mesh of square or rounded shape with a keyhole in the form of a keyhole around the esophagus or separately stitched together semicircular areas in front and behind from the esophagus. The advantage is the possibility of plastic defect not only behind the esophagus, but also ahead of it. The downside of "onlay" by strengthening the cruroraphy with a whole mesh is the high frequency of postoperative complications due to the circular collision of the implant with the Oesophagus, which is amplified by the shrivelling of the mesh, especially when using rigid polypropylene implants. In the Study of Tarragona E. M. and co-authors, where this technique was used, the incidence of dysphagia was $62 \%$ [6].

The fourth surgical technique is the "sublay" technique developed - the strengthening of the posterior cruroraphya, or two-layer alloplasty, in which a triangular implant is sewn behind the esophagus to the legs of the diaphragm on both sides, then the legs are sewn together, completely isolating the mesh from contact with the esophagus. Having experience using this method using lightweight mesh partially dissolving "Ultrapro" implants, it can 
be described as the safest due to the lack of contact of the mesh with the Oesophagus, and at the same time effective in preventing anatomical relapses[7].According to most authors, the main indication of alloplasty is the size of a hernia defect. However, there are no clear indications depending on the size of the defect, no universal method of measuring it, no corresponding classification in the world literature at present, including even in recent reviews and various clinical recommendations, i.e. the sources of the second level of evidence and the high level of recommendations. In clinical recommendations for the treatment of hernias of the esophageal opening of the diaphragm "SAGES" it is indicated that the increase in the area of hernia defect is an independent predictor of the development of relapses[8-10].

\section{Conclusion}

A review of various modern methods of alloplasty has been carried out, major postoperative complications and possible recurrences have been identified. The readings for alloplasty are considered. It was revealed that the optimal technique of alloplasty in large and especially in the giant hernias of the esophageal opening of the diaphragm, which would prevent an anatomical relapse, and at the same time would not cause a food-related complication is not defined. We can assume the following ways to solve these problematic issues: the development of effective and at the same time safe methods of alloplasty large and giant hernias of the diaphragm, the presence of clear indications to alloplast defect, depending on the size of the hernia defect. These tasks can be accomplished through a thorough retrospective comparative analysis of a large clinical material and a prospective randomized trial.

\section{References}

1. Furne EJW (2015) The use of mesh in laparoscopic large hiatal hernia repair: a survey of European surgeons. Surgical laparoscopy, endoscopy, and percutaneous techniques 25(4): 307-311.

ISSN: 2574-1241

DOI: 10.26717/BJSTR.2020.30.004978

I Rosenfeld Fsbou In. Biomed J Sci \& Tech Res

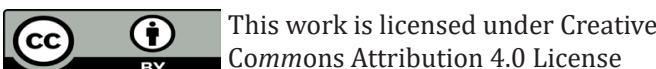

Submission Link: https://biomedres.us/submit-manuscript.php
2. Frantzides CT (2010) Hiatal hernia repair with mesh: a survey of «SAGES» members. Surgical endoscopy 24(5): 1017-1024.

3. VV Grubnik, AV Malinovsky (2015) Critical aspects of laparoscopic surgery of gastroesophageal reflux disease and hernias of the esophageal opening of the diaphragm. Odessa: VVV typography pp: 106.

4. Targarona EM (2013) Long-term outcome and quality of life after laparoscopic treatment of large paraesophageal hernia. World journal of surgery 37(8): 1878-1882.

5. Furne EJW (2013) Mesh in laparoscopic large hiatal hernia repair: a systematic review of the literature. Surgical endoscopy 27(11): 39984008.

6. Stadlhuber RJ (2009) Mesh complications after prosthetic reinforcement of hiatal closure: a 28 - case series. Surgical endoscopy 23(6): 12191226.

7. Rosenfeld II (2018) Remote results of laparoscopic plastics of hyatal hernias. Thesis VI of the All-Russian Intercollegiate Scientific and Practical Conference of Young Scientists with international participation Youth and Medical Science. Tver: FSBOU in Tverskaya GMU of the Ministry of Health of Russia. Council of young scientists and students pp. 56-57.

8. Rosenfeld II (2018) Classification of negative results of laparoscopic operations in hernias of the esophageal opening of the diaphragm. Materials XII of the International Scientific and Practical Conference and students and young medical scientists Youth - Practical Health. Tver: FSBOU in Tverskaya GMU of the Ministry of Health of Russia. Council of young scientists and students pp. 856-858.

9. Rosenfeld II (2018) Laparoscopic plastic in large and giant hernias of the esophageal opening of the diaphragm. Materials of the International Youth Forum dedicated to the 80th anniversary of Stavropol State Medical University Science Week 2018. Stavropol: FSBOU in Stavropol GMU of the Russian Ministry of Health, pp. 408-409.

10. Rosenfeld II (2018) Major problems arising from the plastic herniated esophageal opening of the diaphragm. Materials of the International Youth Forum dedicated to the 80th anniversary of Stavropol State Medical University Science Week 2018. Stavropol: FSBOU in Stavropol GMU of the Russian Ministry of Health, pp. 409-411.

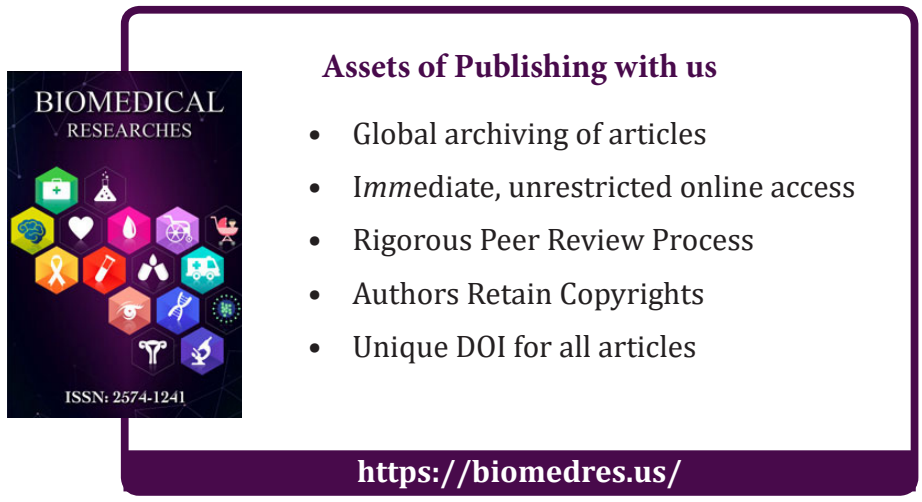

Copyright@ I Rosenfeld Fsbou In | Biomed J Sci \& Tech Res | BJSTR. MS.ID.004978. 